\title{
Clínicas da violência: contribuições da psicanálise
}

\author{
Clinics of violence: contributions of psychoanalysis
}

Ana Clara Daher Carneiro Ferraz, Beatriz Oliveira da Silva, Fábio Santos Bispo, Jaqueline Ribeiro Vargas, Júlia Ott Dutra e Natalia Soares Dalfior.

Universidade Federal do Espírito Santo.

\section{RESUMO:}

$\mathrm{O}$ artigo discute contribuições psicanalíticas para uma clínica da violência, a partir da experiência do projeto de extensão Supervisão clínico-institucional para a equipe do Serviço de Atenção às Pessoas em Situação de Violência de Vitória (SASVV). O projeto, orientado à luz da psicanálise, propõe três eixos de trabalho: político-institucional, teórico-crítico e prático-clínico. Descrevemos a metodologia utilizada, inspirada nas conversações psicanalíticas (MILLER, 2005) e em outras propostas de psicanálise em situações sociais críticas (BROIDE; BROIDE, 2016). Discorremos também acerca de contribuições psicanalíticas para tratar da complexidade envolvida nas situações de violência, como as noções de ancoragens (BROIDE; BROIDE, 2016) e alçamento (GUERRA; MOREIRA, 2020), para pensar estratégias clínicas de trabalho em rede e com os pacientes; e a noção de prática entre vários (DI CIACCIA, 2005), para lidar com a multiplicidade de saberes envolvidos na abordagem clínica da violência.

Palavras-chave: Psicanálise. Clínica da violência. Supervisão clínico-institucional.

\begin{abstract}
:
This paper discusses psychoanalytic contributions to a clinic of the violence, based on the experience of the Clinical and Institutional Supervision extension project for the team of the Service of Attention to People in Situations of Violence in Vitória (SASVV). The project, from a psychoanalytic perspective, proposes three axes of work: institutional politics, theoretical-critical and practical-clinical. We describe the methodology used, inspired in the psychoanalytic conversations (MILLER, 2005) and in others proposals of psychoanalysis in critical social situations (BROIDE; BROIDE, 2016). We also talk about psychoanalytic contributions to address the complexity involved in situations of violence, such as the notions of anchoring (BROIDE; BROIDE, 2016) and lifting (GUERRA; MOREIRA, 2020), to think about clinical strategies for networking and with patients; and the notion of practice among several (DI CIACCIA, 2005), to deal with the multiplicity of knowledge involved in the clinical approach to violence.
\end{abstract}

Key-words: Psychoanalysis. Clinic of violence. Clinical-institutional supervision. DOI: 10.12957/mnemosine.2021.61846

\section{Introdução}

O presente artigo parte da experiência do projeto de extensão Supervisão clínicoinstitucional para a equipe do Serviço de Atenção às Pessoas em Situação de Violência 
de Vitória (SASVV), realizado a partir da perspectiva psicanalítica, vinculado à pesquisa Narrativas sobre a morte violenta: análises teóricas e clínicas de abordagem psicanalítica, financiada por meio do EDITAL CNPq/FAPES No 22/2018 - Programa Primeiros Projetos. A psicanálise tem uma grande contribuição a dar aos profissionais que lidam direta ou indiretamente com a temática da violência, na medida em que se debruça sobre a relação do sujeito com o Outro, sempre atravessada pela linguagem. Se, de um lado, podemos demarcar os impactos violentos da linguagem no corpo falante e no corpo social, por outro, é por meio da fala que nos propomos a operar para tratar a violência e suas marcas traumáticas. Em psicanálise sabemos que a marca subjetiva que o trauma inaugura possui relevância central. Desta forma, pensar as situações de violência produzidas no laço social, bem como os seus efeitos para a constituição dos sujeitos direta ou indiretamente envolvidos é fundamental para criarmos dispositivos clínicos capazes de acolher e dar espaço ao real que se apresenta em meio às circunstâncias potencialmente traumáticas.

Além de apresentar alguns aspectos mais específicos do nosso projeto, pretendemos ampliar a discussão em torno das práticas clínicas voltadas para as situações de violência de uma forma mais geral. Clínicas da violência é, pois, um título que expressa uma leitura dos contextos psicossociais nos quais se dão as diversas formas de violência e, também, as práticas clínicas que se debruçam sobre o mal-estar por elas produzido. Destacamos que é preciso criar sempre novos modos de pensar a violência na cidade e suas manifestações. Ao mesmo tempo, precisamos compartilhar os modos de operar na clínica que têm sido implementados por diferentes serviços e profissionais orientados pela psicanálise.

Na primeira parte deste texto, apresentaremos a proposta do nosso projeto de contribuição com o serviço e, a partir da experiência recolhida nesse tempo, traçaremos uma síntese dos desafios enfrentados e das contribuições teóricas e clínicas que têm orientado a nossa atuação. Esperamos contribuir com outros projetos e serviços que enfrentam o desafio de oferecer suporte psicossocial às pessoas impactadas pelas violências.

\section{Sobre o nosso projeto - Supervisão clínico-institucional}

No município de Vitória/ES, o SASVV lida diariamente com o problema da violência, visando a construção de uma clínica interdisciplinar que seja capaz de 
acompanhar os sujeitos no sentido da ressignificação e reconstrução de suas experiências e vínculos a partir das violências sofridas. O SASVV, criado em 2011 e vinculado à Secretaria Municipal de Saúde de Vitória, é um equipamento ambulatorial multiprofissional composto por médicos, enfermeiras, assistentes sociais, psicólogas, técnicas e auxiliares de enfermagem que promove ações voltadas ao acolhimento, cuidado e atenção em saúde às pessoas em situação de violência residentes no município. Além disso, volta-se também ao trabalho de prevenção e promoção da saúde, atuando não apenas com os sujeitos envolvidos diretamente nas situações de violência, mas também junto a instituições da cidade, como escolas públicas, Unidades Básicas de Saúde, delegacias, guarda municipal, Conselho Tutelar, entre outras.

Com vistas ao fortalecimento das ações desenvolvidas pelo serviço, teve início em 2019 uma parceria entre o SASVV e a Universidade Federal do Espírito Santo (UFES) por meio de um projeto de extensão focado em uma proposta de supervisão clínicoinstitucional direcionada aos profissionais técnicos e gestores da equipe. O objetivo é fornecer suporte teórico-clínico, constituindo um espaço aberto para a construção e reconstrução contínua das políticas e estratégias de trabalho, bem como para o acolhimento das angústias despertadas pelos impasses do real e para a construção de saídas singulares e coletivas.

Uma referência importante para pensar a constituição desse espaço de supervisão foi o trabalho realizado pelo Núcleo de Atenção à Violência (NAV), em Nova Iguaçu, no Rio de Janeiro, por meio do projeto Lugar da Palavra (NAV, 2012). Na experiência carioca, o atendimento clínico se volta a crianças, adolescentes, seus familiares e autores de agressão envolvidos em situação de violência doméstica e/ou risco social. Há também o trabalho de capacitação com profissionais da rede de justiça, assistência social, educação, saúde e conselhos tutelares. Embora haja diferenças em relação ao recorte das violências atendidas e à própria vinculação institucional do projeto com as políticas públicas, encontramos muitos pontos comuns com o trabalho realizado pelo SASVV, que vão desde os objetivos clínicos, voltados à reelaboração das situações de violência e construção de novos laços familiares e sociais, até o papel central de uma orientação de trabalho que valoriza a formação contínua, para a qual a psicanálise fornece os fundamentos basilares: "O trabalho começa com o investimento na formação da própria equipe, que conta com encontros de supervisão semanais não apenas para discutir os casos em atendimento, mas também para se deparar com as dificuldades que os casos colocam para cada um da equipe" (GRYNER; RIBEIRO, 2010: 21-22). 
Seguindo essa direção, nosso projeto de supervisão buscou construir um programa de trabalho que foi desenvolvido em torno de três eixos: a) teórico-crítico; b) políticoinstitucional; e c) prático-clínico. O primeiro pretendeu proporcionar aprofundamento teórico-conceitual sobre as violências na contemporaneidade, bem como seus impactos na subjetividade e no laço social (BISPO, 2018; FREUD, 1930/1996). O segundo eixo diz respeito à reflexão acerca dos princípios e fundamentos do SASVV, sobretudo quanto à sua política norteadora e o seu papel na rede de suporte à violência no município de Vitória. Por fim, o terceiro buscou ofertar acolhimento das experiências vivenciadas pelos profissionais da equipe, propiciando um espaço de circulação da palavra e de construções coletivas para eventuais impasses, bem como a discussão sobre o manejo de casos singulares atendidos pelo SASVV.

De acordo com Ferreira (2010), “A Supervisão clínico-institucional, não é um instrumento estático e acabado, cuja direção já está dada, mas estando em intensa mutação, busca reinventar um saber sobre o necessário - mas problemático laço entre a clínica e a política". Foi nesse sentido que nos propusemos a elaborar, juntamente com a equipe, uma programação flexível para atender às necessidades levantadas e contemplar a complexidade do serviço, buscando manter o compromisso ético com a singularidade dos casos e a contingência das soluções (BISPO, 2012; BISPO, 2014).

Ao mesmo tempo em que surge como pontos de ruptura que podem vir a ser traumáticas, a violência é uma forma de relação dentre tantas outras que vincula vítimas e agressores. Trata-se, pois, de um campo repleto de sutilezas e contradições, de modo que não existe um saber a priori que garanta formas universalizáveis de se lidar com seus efeitos. Nesse sentido, destacamos como norte a importância da circulação da palavra, pois se, por um lado, como propõem Gryner e Ribeiro (2010: 18), “a violência começa quando a palavra perde o valor", por outro lado, a retomada da circulação da palavra, não apenas no acolhimento à população, mas na própria capacitação, só terá um efeito transformador se partirmos do fato de que "o saber que se pode alcançar sobre si mesmo e o próprio trabalho jamais é total ou objetivo, ou seja, sempre é parcial e incompleto" (2010: 21). Nas palavras de Lacan (1972-1973/1985: 130), o saber é “a prender, a ser tomado. É por isso que ele é feito de aprender”. Em suma, não se trata apenas de um serviço de especialista, em que ocorre uma transmissão do saber de um a outro, mas de uma construção contínua e em rede, pois "a conquista desse saber se renova de cada vez que ele é exercido" (p. 130). Nossa proposta foi que o projeto pudesse funcionar como 
mais um ponto de renovação do exercício de saberes que já vinham sendo construídos há alguns anos pela equipe.

\section{Sobre nossa metodologia de trabalho}

Para que essa proposta de construção coletiva e de circulação da palavra pudesse se efetivar, tomamos como norte uma metodologia de trabalho inspirada na lógica das conversações psicanalíticas (MILLER, 2005). De acordo com Miranda, Vasconcelos e Santiago (2006), a conversação, como dispositivo clínico de trabalho, foi inicialmente elaborada por Jacques Alain-Miller para abrir um campo de circulação da palavra entre os psicanalistas. Foi adotada pelo Centro Interdisciplinar de Estudos sobre a Infância (CIEN) como uma prática que possibilitou o exercício da psicanálise aplicada nas escolas, de modo que o saber das crianças e adolescentes era colocado em evidência e, por meio da tomada da palavra, cada um contribuía com as incidências subjetivas que a conversação poderia provocar nos demais participantes. Também a tomamos com essa perspectiva, como uma espécie de "associação livre coletiva, da qual esperamos um certo efeito de saber" (MILLER, 2005: 16). Propusemos que nossos encontros com a equipe multiprofissional fosse construído dessa forma, sempre com um convite ao uso livre da palavra pelos participantes, a partir das questões mais emergentes que pudessem ser evocadas da experiência de trabalho. Por mais que, em determinados momentos, alguns pontos de pauta fossem lançados ou relançados pela própria equipe, estes não se fechavam para as contingências abertas à fala de cada um. Isso também evitava que o supervisor fosse convocado a assumir, ancorado no saber acadêmico, uma posição de mestria, determinando o rumo da experiência coletiva. Principalmente considerando a complexidade em torno da clínica da violência, era imprescindível que os saberes a serem produzidos na supervisão pudessem advir do próprio exercício de interlocução. Mesmo diante de impasses, ou de problemas recorrentes advindos do trabalho em rede e das limitações encontradas no campo das políticas públicas, apostamos nessa perspectiva de que a circulação dos saberes poderia ter o efeito de renová-los, como testemunha Miller a propósito da conversação: “Quando as coisas me tocam, os significantes de outros me dão idéias, me ajudam e, finalmente, resulta — às vezes — algo novo, um ângulo novo, perspectivas inéditas" (MILLER, 2005: 16).

Para efetivar essa proposta por meio de um trabalho coletivizado, tomando-o como um instrumento clínico, adotamos a prática proposta por Jorge Broide e Emília Broide (2016) em Notas para um trabalho grupal. Os autores destacam duas funções 
operativas na condução dos grupos: a do coordenador e a dos cronistas. O coordenador seria aquele que se oferece como "suporte daquilo que os integrantes do grupo lhe adjudicam" (2016: 53), ou seja, é o personagem que se disponibiliza à escuta do outro, manejando as diferentes transferências que emergem no espaço compartilhado a fim de que possam advir as singularidades de cada um. Mais do que falar, a função do coordenador é manter viva a função do enigma, sustentando perguntas que possam provocar o movimento de trabalho. A função dos cronistas é a de "instaurar a escuta clínica no grupo como aporte metodológico que entrelaça a escuta à escrita, colocando em relevo a palavra" (2016: 54). Significa dizer que esses personagens escrevem sobre o que se passa no interior do grupo, fornecendo material para as elaborações seguintes. A crônica, resultado do movimento transferencial que une escuta e escrita, é, então, o motor onde se encontram os significantes necessários para a construção de hipóteses e dispositivos de intervenção. As extensionistas integrantes do projeto foram convidadas a sustentar a função de cronistas, de modo a permitir com que as falas dispersas nos encontros pudessem prosseguir reverberando nas construções posteriores acerca da direção do trabalho, que seriam então relançadas à equipe.

Durante o ano de 2020, em decorrência do avanço da pandemia da COVID-19 e o início da quarentena, as supervisões com a equipe multidisciplinar passaram a acontecer de forma remota, por meio de uma plataforma virtual. Isso gerou certo impacto no funcionamento do grupo e demandou uma reorganização das atividades. A maior parte da equipe continuou a se reunir presencialmente no espaço do SASVV, enquanto os outros profissionais, assim como o coordenador, as extensionistas, e os gestores participaram virtualmente. As angústias e incertezas ocasionadas pela pandemia acabaram tomando a cena nesse primeiro momento, uma vez que muitas atividades tiveram que ser suspensas. Havia ainda o risco de contágio ao qual os profissionais se expunham cotidianamente; as mudanças emergenciais realizadas para o atendimento aos casos de COVID; profissionais que precisaram ser remanejados para o trabalho remoto; serviços da rede que haviam sido suspensos; em resumo, situações que traziam questões não apenas relativas à condução dos casos, mas à própria saúde mental de cada trabalhador. Apesar de algumas dificuldades, foi importante manter os encontros online nesse período, pois eles funcionaram como um acolhimento a essas angústias e como um espaço de redesenho das estratégias de trabalho do SASVV. Embora o trabalho à distância tenha dificultado em alguns pontos a fluidez da circulação da palavra, facilitaram em 
outros, como pode ser visto na atividade das cronistas. A produção das crônicas realizada nesses encontros, tendo em vista os dispositivos online, que permitem uma escrita conjunta simultânea, possibilitou maior detalhamento das reuniões e que outras afecções fossem colocadas ao longo do texto, com a criação de um arquivo com diferentes visões a respeito de um mesmo momento.

\section{O que fizemos e o que apreendemos}

Nesta parte, exporemos brevemente o trabalho realizado, buscando destacar os três eixos mencionados acima. Mais do que relatar o que foi feito ou as questões que foram abordadas pela equipe, o mais importante é realizar uma síntese do que pudemos aprender com a experiência para pensar os desafios relacionados com uma clínica das violências. Nesse sentido, esse texto representa uma construção teórico-clínica que se inicia com as questões e os debates realizados na equipe multiprofissional; prossegue nos encontros com os gestores e grupos específicos de trabalho que se reuniram para supervisões pontuais; é ruminado com o grupo de extensionistas que registraram a experiência e promoveram sobre ela diversas reflexões; e se conclui com o exercício da escrita de um artigo e a transformação da experiência em um saber transmissível.

O eixo que denominamos político-institucional foi longamente trabalhado, de modo que ocupou quase que exclusivamente todo o primeiro semestre do projeto e retornou mais pontualmente nos semestres subsequentes. Pode-se dizer que a sustentação política de um trabalho com a violência no setor público é um desafio constante que nunca estará totalmente superado. A experiência de supervisão suscitou diversas questões sobre a função do serviço e sua inserção na política de atenção às pessoas em situação de violência. Para respondê-las, entretanto, precisávamos recorrer aos fundamentos teóricos e clínicos de nossa prática, de modo que as três dimensões se tornaram efetivamente entrelaçadas.

Nossa estratégia para o eixo teórico-crítico contemplou a realização do curso de extensão Clínicas da Violência, para o qual convidamos, além dos profissionais do SASVV, trabalhadores de outras instituições interessados na temática. Desse modo, além de uma formação teórica, pudemos consolidar a interação entre diversos atores da rede de cuidado. Desafios da atuação em rede puderam ser debatidos com profissionais dos serviços da capital e da região metropolitana. O Seminário Clínicas da Violência: modos de pensar, modos de operar possibilitou o fechamento desse eixo, articulando-o com a nossa pesquisa em um intercâmbio com o Núcleo de Psicanálise e Laço Social no 
Contemporâneo - PSILACS, da UFMG, e o Grupo de Pesquisa Psicanálise: Clínica e Laço Social, da UFES. O público foi composto principalmente por profissionais da área de saúde e por estudantes de graduação e pós-graduação.

O eixo prático-clínico também foi contemplado com o início da construção, pela própria equipe do SASVV, de protocolos clínicos orientadores da articulação em rede. O exercício dessa construção se deu também na efetivação direta de estratégias de trabalho, como a organização de duplas de profissionais para articulação com os territórios. Também houve supervisão de casos clínicos com a equipe multiprofissional, além do acolhimento das angústias dos profissionais diante das incertezas e mudanças ocasionadas pela pandemia em 2020. Temos focado atualmente no estudo da ampliação dos dispositivos clínicos, privilegiando seu caráter multidisciplinar. Compusemos, com os gestores, um grupo de trabalho para consolidar as diretrizes clínicas do serviço, fazendo uma ponte entre as construções propostas pela equipe e as diretrizes institucionais. Avaliamos que essa atuação junto aos gestores pode ajudá-los na escuta das demandas da equipe, bem como ajudar a equipe a escutar as demandas da gestão, para além de seus aspectos burocráticos e administrativos. Nesse ponto, o eixo clínico se entrelaça com a dimensão político-institucional, na medida em que o respaldo institucional dá corpo e efetividade às direções propostas para o trabalho. É a consolidação de uma política da clínica que permitirá a construção de um trabalho orientado, passível de ser sustentado mesmo diante de eventuais mudanças nas políticas administrativas.

A seguir, elencamos alguns pontos que foram sustentados como questões que interrogam o lugar do SASVV na rede de atenção à violência, bem como a concepção de uma proposta clínica multidisciplinar. Esses pontos atravessam os três eixos do trabalho e surgiram geralmente vinculados aos casos singulares que acabavam por desafiar os protocolos.

A) O serviço deve acolher diferentes tipos de violência, de públicos diversos, ou seria melhor focar na violência sexual contra crianças e adolescentes?

Percebemos que essa indefinição não era casual, mas se encontrava na própria constituição do serviço. Embora, em sua concepção e no próprio nome, tenha sido mantida uma abertura ao atendimento a outras formas de violência, sua vinculação inicial a um Pronto Atendimento e aos protocolos de violência sexual acabaram estabelecendo um recorte na prática. Além disso, o município conta com outros serviços 
disponibilizados na rede para tratar violências físicas e psicológicas contra mulheres, como as delegacias especializadas e equipamentos de assistência social, de modo que o SASVV acabou se constituindo como uma referência relacionada, sobretudo, à violência sexual contra crianças e adolescentes. O desafio no enfrentamento dessa questão está justamente em construir um enlace entre os planos da gestão - que precisa levar em conta a dinâmica da rede como um todo -; o acúmulo de saber sustentado na equipe, bem como os receios diante do que não se pode saber; e a concepção que a rede e os usuários constroem do serviço ao longo do tempo.

B) O foco deve ser a violência aguda ou as violências crônicas?

A vinculação com o Pronto Atendimento parecia um elemento que pendia para um foco em situações agudas e à limitação do tempo de permanência do usuário no serviço. Entretanto, os casos acolhidos frequentemente descortinavam um histórico de violências e violações dentro do contexto psicossocial dos pacientes e de suas famílias que precisavam ser consideradas. A violência sexual, relatada como um novo acontecimento, remete a outras formas de violência, muitas vezes invisível, das quais não pode ser desconectada. Daí a importância na aposta de um acompanhamento mais processual.

C) Como encontrar, junto com as redes de saúde, educação e assistência, bem como com os próprios pacientes, pontos de suporte para superação da violência?

Esse ponto surge não apenas em termos do planejamento de frentes de trabalho para aproximar o serviço dos equipamentos públicos, mas também na definição do tempo de acompanhamento de cada caso, no retorno dos casos para o território, na busca ativa do paciente e de eventuais figuras de referência para o sujeito, e até na definição do momento de concluir um acompanhamento.

D) Como escapar da fragmentação e especialização dos saberes?

Essa questão diz respeito tanto ao lugar de suposição de saber relativo a um serviço especializado quanto à própria interação entre os saberes específicos de cada profissional na equipe. A violência, sobretudo a sexual, é sempre uma temática difícil que tende a ser silenciada. Não apenas os pacientes encontram barreiras psíquicas para elaborá-las e para encaminhar uma demanda de cuidado para um Outro, mas os próprios profissionais de saúde, por vezes, não suportam esse lugar de acolhimento da angústia 
decorrente da violência. O encaminhamento de pacientes para uma equipe especializada pode, muitas vezes, surgir menos como um plano clínico de cuidado e mais como uma evitação. De algumas instâncias também surgem demandas de avaliação, cujo foco está mais na investigação dos fatos do que no acolhimento terapêutico dos pacientes. Também é recorrente a situação em que a demanda é dirigida exclusivamente ao psicólogo, como se o único cuidado possível fosse uma psicoterapia, ou como se o psicólogo fosse o único especialista capaz de escutar e acolher o sofrimento subjetivo. Manejar esse lugar da suposição de saber é, pois, um desafio tanto na relação com outros profissionais da rede como na relação entre os próprios componentes da equipe.

Todos esses pontos podem estar presentes em maior ou menor grau em outros serviços que lidam diretamente com a violência. Delimitar uma proposta políticoinstitucional; lidar com a complexidade do fenômeno da violência, para além do que é imediatamente visível; construir estratégias clínicas de trabalho em rede e com os pacientes; e lidar com a transferência destacada na suposição de saber que o lugar institucional engendra são desafios cotidianos importantes que decantamos desse tempo de trabalho. Com o advento da pandemia, surgiram novas questões e desafios específicos sobre o funcionamento do serviço. Por conta da instabilidade presente na rede de saúde e de assistência, que trouxe dificuldades para o encaminhamento de alguns casos, e com a diminuição inicial do número de pacientes, foi importante trazer o foco para o acolhimento das angústias dos próprios profissionais. Alguns projetos que já vinham sendo encaminhados precisaram ser paralisados ou repensados, o que impactou o planejamento da equipe, mas também abriu um tempo para compreender, ocasião em que muitas das questões acima expostas foram retomadas e elaboradas.

\section{O que nos tem orientado}

Desde o início do trabalho foram destacadas as principais bases teóricas orientadoras do projeto. Partimos da psicanálise e do que podemos denominar de uma psicanálise implicada (BISPO, 2014; GUERRA; BEMFICA, 2020), tanto com a dimensão política do sofrimento psíquico quanto com os diferentes saberes que se articulam para a construção do que temos chamado de uma clínica da violência. Para além de uma aplicação técnica de um saber acadêmico, a psicanálise se abre à contingência dos encontros para construir intervenções que subvertam as lógicas de dominação reinantes no laço social, produtoras das violências cotidianas. Nesse sentido, em vez de ofertar um 
programa teórico prévio de estudos, o movimento que realizamos foi o de buscar, a partir das questões suscitadas pelas conversações nas supervisões, referências teóricas que pudessem subsidiar nossas construções e orientar as intervenções.

No decorrer do projeto recorremos a diversas referências teóricas para abordar questões específicas concernentes a temas como: a) o mal-estar, o sofrimento e os sintomas (DUNKER, 2011) relativos à violência; b) a violência sexual e projetos voltados para o tratamento da violência (GRYNER e RIBEIRO, 2010; CUNHA, 2014); c) estudo da violência a partir da psicanálise (BISPO, 2018); d) oficinas e trabalho com crianças e adolescentes em contexto de violência (BISPO; PIMENTEL, 2019; DOUVILLE, 2019; MOREIRA, 2020), dentre outras. É importante enfatizar, entretanto, no espaço deste artigo, algumas referências que respondem diretamente aos desafios elencados na seção anterior. Como os dois primeiros se relacionam mais com a conjuntura própria da organização da rede, destacamos os dois últimos, letras C) e D), para os quais encontramos propostas bastante consistentes no campo da psicanálise.

\section{Como encontrar pontos de suporte para a superação da violência?}

A perspectiva de saúde que se busca trabalhar no SUS parte de uma definição ampliada, que inclui os diversos condicionantes sociais e históricos que atravessam a vida dos sujeitos. A saúde, vista como produtora e produto de uma complexa rede, convoca novos dispositivos para a atuação das equipes, e, nesse sentido, a construção de redes entre os serviços se torna estratégia indispensável ao cuidado (BRASIL, 2009). Dessa forma, cada serviço e equipamento torna-se um "nó" interdependente na rede de atenção à saúde, que se liga a outros "nós" a fim de viabilizar suas ações. Esse entrelaçamento convida os atores envolvidos no processo a um constante movimento de (re)construção de redes vivas, não estáticas, posto que acolhem a diferença e voltam-se às singularidades de cada sujeito imerso numa teia de relações (BRASIL, 2009). Quinderé, Jorge e Franco (2014: 255), ao falarem de rede no contexto da saúde mental, falam de um tipo de rede "que se constitui sem modelo, que não parte de uma estrutura, pois se constrói em ato, com base no trabalho vivo de cada trabalhador e equipe, mediante fluxos de conexões entre si, na busca do cuidado em saúde".

Essa proposta condiz com o que denominamos de uma ética da contingência (BISPO, 2012; 2014), que inspira a atuação da psicanálise no campo social, uma vez que valoriza as invenções em detrimento dos modelos prévios. Uma lógica da contingência permite justamente que "aquilo que não pode ser padronizado (impossível de se escrever) 
apareça e encontre uma solução circunstancial (às vezes se escreva) em seu próprio campo" (p. 84). Ainda que o serviço não prescinda totalmente de protocolos e diretrizes, estes não devem suprimir as soluções circunstanciais criadas pela equipe e pelos próprios pacientes, “mesmo que essas soluções não sejam generalizáveis, não sirvam para todos, mesmo que até pareçam ridículas, é importante que elas sejam escutadas e aventadas como possibilidade para aquele que padece" (p. 84).

O espaço de supervisão clínico-institucional, quando focado na escuta dos casos clínicos compartilhados pela equipe, também facilita uma abordagem que vise a percepção integral do sujeito, como é proposto pelas políticas do SUS. Ao compartilhar o que foi apreendido a partir da escuta do sofrimento, é possível discutir a quais pontos na história do sujeito ele pode se agarrar, para conseguir não ser tragado pelo impacto traumático da violência. Trata-se de encontrar, junto com os atores envolvidos, pontos de ancoragem (BROIDE; BROIDE, 2016) e, com isso, novos encaminhamentos a serem tomados dentro da rede de saúde e assistência.

A noção de ancoragens, proposta por Broide e Broide (2016) ao discutir o atendimento em situações sociais críticas, mostra-se como uma rica contribuição para o acolhimento de pessoas em situação de violência, ainda mais quando se destaca que grande parte das violências sexuais são intrafamiliares. Se a família, em muitos casos, geralmente funciona como um suporte que vincula o paciente a seu tratamento, quando ela se constitui como fator reprodutor de violência, é preciso avaliar as alternativas disponíveis para cada caso. "É a família? Namorada, namorado? Vive no bairro? Onde vive?", exemplificam os autores e concluem de maneira contundente: "é necessário que encontremos quem de fato deseja que este adolescente viva!" (BROIDE; BROIDE, 2016: 33, grifo dos autores).

Propõe-se uma análise dos vínculos do sujeito com a comunidade, os equipamentos públicos e com as próprias atividades propostas pelo serviço, de forma a encontrar esses pontos específicos que o mantém vivo, a partir de um trabalho intenso da rede no território. Para ser realizado, esse trabalho depende de uma escuta da relação transferencial do sujeito com os técnicos, no sentido de se investir nos vínculos mais potentes, independente da especialidade de cada um. É preciso considerar que as saídas não podem ser garantidas por protocolos ou modelos pré-definidos de atuação. Ao escutar o sujeito, é possível "mapear estes fios que se embrenham pelo território físico e psíquico" (BROIDE; BROIDE, 2016: 30), de forma a relacioná-los ao seu desejo e sua relação com 
a comunidade. Portanto, pensar uma ação no território não se resume a demandar da família um suporte muitas vezes impossível, mas sobretudo investir em dispositivos outros, tais como a escola, vizinhos, pessoas da comunidade, setores públicos e privados que frequenta, dentre outras possibilidades.

Essa formulação acerca das ancoragens nos remeteu também à noção de alças e saídas, proposta por Moreira et al. (2020) a propósito da função da escola na vida de adolescentes com trajetória infracional. A articulação do serviço com os diversos dispositivos da rede também permite o encontro com experiências que alavanquem o sujeito para fora da situação de violência. Essa função se inspira na lógica de alçamento, proposta inicialmente por Célio Garcia (2010 apud MOREIRA et al., 2020: 8), para evocar uma ideia de "elevação, alteração (saída) de uma posição mais subordinada para uma outra mais favorável", que seria proporcionada pela construção com o sujeito de um saber inédito, capaz de impulsionar a busca por outras saídas ainda não cogitadas, permitindo um direcionamento para alçar novos horizontes.

Ademais, é importante destacar como Costa (2014: 22) explana que "não lhe interessa localizar o déficit ou a carência, mas potencializar os recursos com os quais os sujeitos já contam, de modo que possa haver condições de fazer valer recursos simbólicos em proveito próprio". Sendo assim, o serviço entra como articulador dessas possibilidades, ou seja, após entender quais os pontos de ancoragem do sujeito, nos quais ele pode se segurar e encontrar apoio para se restabelecer, o desafio passa a ser construir dispositivos que também sirvam de alavanca e o ajudem a projetar outras perspectivas para o futuro. "O churrasqueiro, a dança, a capoeira, o rap", sugerem Guerra e Moreira (2020: 183), "numa função não necessariamente vertical nem também horizontal, atravessam, singularmente, o corpo pulsional adolescente, de onde o órgão da linguagem faz gozo e impõe, a cada um, uma nova resposta desejante".

A articulação com a rede mostra-se fundamental nesse quesito, no sentido de se vislumbrar, junto com outros equipamentos, ferramentas como grupos, oficinas, atividades culturais, atendimentos clínicos, entre outros, por meio dos quais o sujeito possa se deparar com experiências que os mobilizem a construir conjuntamente novas saídas, nas quais buscam, "com o acompanhamento, ampliar os recursos simbólicos já disponíveis e possibilitar a construção de novas respostas diante dos embaraços" (COSTA, 2014: 22). Esperamos, portanto, que o sujeito encontre de forma ativa e participativa outras possibilidades que façam sentido para ele, ao se desvencilhar dos rótulos e marcas advindos da situação de violência. 


\section{Como escapar da fragmentação e especialização dos saberes?}

O primeiro desafio com que nos deparamos na condução da supervisão foi justamente relacionado à diversidade de saberes em jogo numa equipe multiprofissional. Como garantir um trabalho que não privilegiasse a psicologia em detrimento de outros saberes? Que contribuições alguém que não está diretamente inserido na rede de saúde mental poderia ofertar para profissionais com trajetórias tão ímpares e marcantes? A aposta que sedimentou a parceria foi justificada exatamente pela importância que um olhar externo orientado pela psicanálise poderia representar. A demanda não era, pois, de um mestre que viesse dirigir o trabalho, mas de um lugar que pudesse funcionar como ponto de articulação dos saberes já existentes. Para tanto, foi importante suspender a tendência universitária de apresentar um saber e colocar em ação a lógica psicanalítica da circulação da palavra.

Tendo a psicanálise como direção de trabalho, é importante que esse deslocamento também ocorra na relação que os técnicos estabelecem com o próprio trabalho e com os pacientes, de modo a evitar que cada um se enclausure na segurança de sua especialidade. Para pensar esse desafio, recorremos a uma proposta que ficou conhecida como "a prática entre vários" (DI CACCIA, 2005; RODRIGUES, 2016). “Trata-se de uma proposta metodológica fundamentada na inversão do eixo do saber, considerando que, nas instituições em geral, o saber está do lado da equipe técnica" (RODRIGUES, 2016: 111). Como propõe Stevens (2007), o psicanalista não se coloca como mais um especialista ao lado de outros, como especialista da subjetividade, do sofrimento psíquico ou do gozo. Pelo contrário, "ele é desespecializante, ele fura a instituição e o trabalho analítico através de uma construção do caso que atravessa todos os pontos de vista dos especialistas" (STEVENS, 2007: 79). Tal metodologia visa criar uma lógica clínica do caso, em que o saber que importa é aquele veiculado pelas invenções do sujeito. É importante ressaltar, apesar disso, que cada profissional é responsável pelo seu discurso e por inventar também sua própria forma de situar-se coletivamente. "Em uma prática entre vários", enfatiza Di Caccia (2007: 73), “cada um é responsável pelo seu ato, e na primeira pessoa".

Essa lógica é importante também na relação que a equipe mantém com os demais atores da rede, como conselhos tutelares, escolas, centros de saúde, dentre outros. Quando se adota a postura, muitas vezes demandada de uma equipe especializada em violência, de dizer o que o outro deve fazer, a tendência é se acirrarem as resistências e evitações 
diante do mal-estar. Quando há abertura para que cada um relate os impasses que a situação de violência acarreta, potencializam-se os saberes que podem contribuir com a condução dos casos. Daí a importância de uma das frentes de trabalho sustentadas pelo SASVV, focada na capacitação também como um espaço de circulação da palavra.

Percebemos que, para sustentar cotidianamente essa lógica de trabalho, não bastam as iniciativas individualizadas, é preciso inventar dispositivos clínicos inspirados nessa desespecialização e na possibilidade de interação entre os saberes. Como constatado por um projeto de extensão de escuta clínico-política de sujeitos em situações críticas, "O desafio, então, é desenvolver aparatos de circulação da palavra por meio da oferta de escuta, como rodas de conversa e oficinas, em suas articulações com as manifestações culturais e artísticas" (IMBRIZI et. al., 2020, p. 10), com o objetivo de despertar nos jovens "o seu desejo de viver". Justamente devido às marcas traumáticas que podem ser deixadas pelas situações de violência, o modelo tradicional de consultório pode não ser suficiente para o estabelecimento de uma transferência capaz de permitir um endereçamento a um Outro. Nas palavras de Douville (2019: 20), pode ser necessário "retomar o gosto pela presença de um outro falante", o que pode ser particularmente difícil quando o sujeito se vê confrontado por um outro que quer arrancar dele a qualquer custo uma verdade sobre uma violência sofrida. Broide e Broide (2016: 49) também destacam essa preocupação com "a construção de diferentes settings que possibilitem emergir o sujeito de desejo". Destaca que, em grande parte, esses dispositivos são grupais, mas também podem ser individuais ou informais, abertos às contingências do encontro. Pode ser até mesmo "um trabalho de escuta através de uma caminhada pelas ruas em contatos pontuais com os atores do território estudado" (BROIDE; BROIDE, 2016: 48).

\section{Nossas considerações finais}

Este artigo buscou, para além de um relato de experiência, decantar os principais desafios e contribuições teóricas que o campo psicanalítico tem produzido nos últimos anos para dar conta de uma clínica que aqui denominamos de clínica da violência. Se pudemos ocupar esse lugar da supervisão de um serviço multiprofissional a partir do saber da psicanálise, foi somente na medida em que essa contribuição não se encaminhou no sentido de uma pedagogia da assistência ou de uma psicologia da violência. Isso significa que não nos propomos a ensinar métodos de atendimento nem teorias acerca das violências e suas incidências subjetivas. Nossa principal contribuição parece ter se encaminhado para a sustentação de uma política do desejo, que valoriza as enunciações 
subjetivas, acima das demandas utilitárias ou institucionais (BISPO, 2014). Muitas vezes, as políticas públicas encontram-se divididas entre as demandas administrativas e as enunciações subjetivas, de modo que as primeiras tendem a silenciar as últimas. Quando se trata do atendimento a pessoas em situação de violência, esse silenciamento pode ser ainda mais sistemático, na medida em que as necessidades investigativas ou de punição e controle da violência podem sobrepor-se ao tempo subjetivo de elaboração necessário a uma superação efetiva da violência. Daí a importância estratégica de se ter um serviço como o SASVV, pensado para lidar com a complexidade que uma clínica da violência exige. Por mais que sempre haja o desafio da suposição de saber, que pode levar outros profissionais e equipamentos a buscar o serviço para evitar escutar as marcas da violência, é ao manejar essa transferência que a equipe pode contribuir para que dispositivos de escuta sejam fomentados na rede, de maneira que a política seja a de não recuar diante da violência e de seus efeitos. Dessa forma, podem ser subvertidas as marcas e estigmas instituídos nas trajetórias subjetivas e respeitadas as saídas construídas em cada caso, não sem o ato, a voz e a responsabilidade de cada um.

\section{Referências}

BISPO, Fábio Santos. Ética da contingência: a lógica da ética da psicanálise. Curitiba: Juruá Editora, 2012.

BISPO. Fábio Santos. A ética da contingência e a implicação da psicanálise no laço social. Psicologia Revista, vol. 23, n 1,2014 . pp. 75-95.

BISPO, Fábio Santos. Morte violenta: modalidades de apresentação no laço social. Curitiba: Editora CRV, 2018.

BISPO, Fábio Santos.; PIMENTEL, Sabrina Gusmão. Oficinas Terapêuticas de Imaginação. Revista Guará, ano 7, nº 11, julho de 2019. pp. 95-104.

BRASIL. Redes de produção de saúde. Brasília: Ministério da Saúde, 2010.

BROIDE, Jorge; BROIDE, Emília. A psicanálise em situações sociais críticas: metodologia clínica e intervenções. 2.ed. São Paulo: Escuta, 2016.

COSTA, Débora Matoso. Jovem: infrator?: a experiência do Projeto SELEX. 2014. 83f. Dissertação (Mestrado) -- Faculdade de Filosofia e Ciências Humanas, Universidade Federal de Minas Gerais. Belo Horizonte. 2014.

CUNHA, Cristiane de Freitas. A janela da escuta. Belo Horizonte, MG: Scriptum, 2014.

DI CIACCIA, Antônio. A prática entre vários. In: ALTOÉ, Sônia; DE LIMA, Márcia Mello. (Orgs.). Psicanálise, clínica e instituição. Rio de Janeiro: Rios Ambiciosos, 2005.

DOUVILLE, OLIVIER. Violências e violações impertinentes - a experiência do estrangeiro em terra de rei com um olho só. In: GUERRA, ANDRÉA MÁRIS 
CAMPOS; OTONI, MARINA SOARES; PENNA, PAULA DIAS MOREIRA (Orgs.). Violências e violações impertinentes - Direito e Psicanálise IV. Belo Horizonte: Scriptum, 2019. pp. 11-20.

DUNKER, Christian Ingo Lenz. Estrutura e constituição da clínica psicanalítica: uma arqueologia das práticas de cura, psicoterapia e tratamento. São Paulo: Annablume, 2011.

FREUD, Sigmund. O mal-estar na civilização (1930 [1929]). Edição Standard. Brasileira das Obras Completas de Sigmund Freud, vol. XXI. Rio de Janeiro: Imago, 1996.

GRYNER, Simone; RIBEIRO, Paula Mancini. A escuta que escreve história. Rio de Janeiro: Núcleo de Atenção à Violência (NAV), 2010.

GRYNER, Simone; RIBEIRO, Paula Mancini (Orgs.). Revista NAV - Núcleo de atenção à violência. Rio de Janeiro, 2012.

GUERRA, Andréa Máris Campos; MOREIRA, Jacqueline de Oliveira (Orgs.). Adolescências e narrativas memorialísticas: escutando apostas inconscientes. Santa Cruz do Sul: EDUNISC, 2020.

GUERRA, Andréa Máris Campos; BEMFICA, Aline. (Orgs.). Psicanálise implicada e adolescência: modos de intervenção e testemunhos clínicos. Curitiba, PR: Editora CRV, 2020.

IMBRIZI, Jaquelina Maria et. al. O projeto de extensão "Escuta clínico-política de sujeitos em situações sociais críticas" e a roda de conversa sobre cultura hip-hop. In: MOREIRA, Jacqueline de Oliveira (Org.). Juventudes e contemporaneidade: reflexões e intervenções. Santa Cruz do Sul: EDUNISC, 2020. (Coleção Coletivo amarrações: psicanálise e políticas com juventudes).

LACAN, Jacques. O Seminário, livro 20: mais, ainda (1972-1973). $2^{\text {a }}$ edição revista. Tradução: M. D. Magno. Rio de Janeiro, RJ: Jorge Zahar, 1985.

MILLER, Jacques-Alain et al. La pareja e el amor: conversaciones clinicas com Jacques Alain-Miller em Barcelona. $1^{\mathrm{a}}$ ed. Buenos Aires: Paidós, 2005. p.15-20

MIRANDA, Margarete Parreira, VASCONCELOS, Renata Nunes; SANTIAGO, Ana Lydia Bezerra. Pesquisa em psicanálise e educação: a conversação como metodologia de pesquisa. Psicanálise, educação e transmissão, 6, 2006, São Paulo. Disponível em: <http://www.proceedings.scielo.br/scielo.php?script=sci_arttext\&pid=MSC0000 $000032006000100060 \& \operatorname{lng}=\mathrm{en} \& n \mathrm{~mm}=\mathrm{abn}>$. Acesso em 30 out. 2020.

MOREIRA, Jacqueline de Oliveira et al. Ambivalência da escola e adolescentes infratores. Psicologia Escolar e Educacional, Maringá, v. 24, 2020. Disponível em: $\quad<$ http://www.scielo.br/scielo.php?script=sci_arttext\&pid=S1413$85572020000100308 \& \operatorname{lng}=\mathrm{en} \& \mathrm{nrm}=\mathrm{iso}>$. Acesso em 06 nov. 2020.

MOREIRA, Jacqueline de Oliveira (Org.). Juventudes e contemporaneidade: reflexões e intervenções. Santa Cruz do Sul: EDUNISC, 2020. (Coleção Coletivo amarrações: psicanálise e políticas com juventudes).

QUINDERE, Paulo Henrique Dias; JORGE, Maria Salete Bessa; FRANCO, Túlio Batista. Rede de Atenção Psicossocial: qual o lugar da saúde mental? Physis, Rio de Janeiro, v. 24, n. 1, março de 2014. p. 253-271

RODRIGUES, Adriana. Algumas considerações sobre a prática entre vários. Arteira - 
revista de psicanálise, $\mathrm{n}^{\circ}$ 8, 2016. pp. 111-116.

STEVENS, Alexander. A instituição: a prática do ato. In: MILLER, Judith; MATET, Jean-Daniel. Pertinências da psicanálise aplicada: trabalhos da Escola da Causa Freudiana reunidos. Rio de Janeiro: Forense Universitária, 2007.

Ana Clara Daher Carneiro Ferraz

Universidade Federal do Espírito Santo (UFES)

Email: anadferraz@gmail.com

Beatriz Oliveira da Silva

Universidade Federal do Espírito Santo (UFES)

Email: biaoliveira.md@gmail.com

Fábio Santos Bispo

Universidade Federal do Espírito Santo (UFES)

Email: fabio.bispo@ufes.br

Jaqueline Ribeiro Vargas

Universidade Federal do Espírito Santo (UFES)

Email: jaqueline.rvargas@ outlook.com

Júlia Ott Dutra

Universidade Federal do Espírito Santo (UFES)

Email: juliaott_dutra@hotmail.com

Natalia Soares Dalfior

Universidade Federal do Espírito Santo (UFES)

Email: nataliasdalfior@gmail.com 